\title{
GCU
}

Glasgow Caledonian

University

University for the Common Good

\section{Effects of humidity on tests of tear production}

Buckmaster, Fiona; Pearce, E. Ian

Published in:

Cornea

DOI:

10.1097/ICO. 0000000000000818

Publication date:

2016

Document Version

Author accepted manuscript

Link to publication in ResearchOnline

Citation for published version (Harvard):

Buckmaster, F \& Pearce, El 2016, 'Effects of humidity on tests of tear production', Cornea, vol. 35, no. 6, pp. 754-758. https://doi.org/10.1097//CO.0000000000000818

\section{General rights}

Copyright and moral rights for the publications made accessible in the public portal are retained by the authors and/or other copyright owners and it is a condition of accessing publications that users recognise and abide by the legal requirements associated with these rights.

Take down policy

If you believe that this document breaches copyright please view our takedown policy at https://edshare.gcu.ac.uk/id/eprint/5179 for details of how to contact us. 


\title{
The effects of humidity on tests of tear production.
}

\author{
Fiona Buckmaster \\ Glasgow Caledonian University, Glasgow, UK \\ E. Ian Pearce $(\mathrm{PhD})$ \\ Glasgow Caledonian University, Glasgow, UK \\ Department of Vision Sciences \\ Glasgow Caledonian University \\ Cowcaddens Road \\ Glasgow \\ G4 0BA \\ United Kingdom
}

Corresponding author: fiona@ buckmaster.co.uk; +44 7884197983

Author to receive reprints: e.i.pearce@gcu.ac.uk; +44 1413318201

There is no conflict of interest.

This investigation was funded by a summer research scholarship to Fiona Buckmaster by CooperVision UK.

Key words: Schirmer test, relative humidity, dry eye disease, tear production 


\section{$\underline{\text { Abstract }}$}

Purpose: To determine if the Schirmer test is affected by environmental humidity, to quantify any effects, and consider the ways in which this may affect the diagnosis of dry eye disease.

Methods: All experiments took place within a controlled environment chamber at a range of 5\% to 95\% relative humidity $(\mathrm{RH})$. In vitro testing immersed Schirmer strips at a $5 \mathrm{~mm}$ depth in water for five minutes. In vivo tests were conducted using the standard clinical method. All experiments were conducted using both standard Schirmer strips and Schirmer strips sheathed in a plastic film in order to reduce the possible effects of evaporation.

Results: In vitro results showed a clear decrease in Schirmer wetting length as RH was reduced. Schirmer test strips that were encased within a plastic sheathing were less affected by changing RH. As well as wetting length, the rate of wetting of Schirmer strips was also affected by changes in RH. In vivo data showed that Schirmer results in participants with severe dry eye disease were less affected by changes in RH than "normal" participants.

Conclusion: Patients with severe dry eye disease produce Schirmer test results which are unaffected by environmental humidity. However, patients with moderate Schirmer wetting lengths may be falsely diagnosed as having dry eye disease if their test is undertaken in a low humidity environment. This phenomenon may be overcome with the use of plastic sheathing. Previous studies investigating the effects of environmental conditions upon the tear film may have been affected by this phenomenon. 


\section{$\underline{\text { Introduction }}$}

Dry eye disease is a multifactorial disorder that results in tear film instability, ocular discomfort, and frequently causes ocular surface damage. ${ }^{1}$ Aqueous deficient dry eye disease can be identified and assessed by measuring tear production, and as such the Schirmer test (ST) has been a staple of both clinical practice and research methodology since its first description in $1903 .^{2}$ The popularity of the Schirmer test has been attributed to its relative simplicity and low cost when compared to alternative methods of assessing tear production ${ }^{3}$. However, despite its widespread use, the Schirmer test has a number of shortcomings which are well recognised, ${ }^{3-7}$ including poor reproducibility and poor patient comfort.

The Schirmer test is performed by placing the folded end of a strip of filter paper of $5 \mathrm{~mm}$ width over the inferior lid margin on the temporal side, where it is left for a duration of five minutes, after which the wetting length of the strip is measured. The application of this filter paper produces a degree of discomfort for the patient, ${ }^{8}$ which is often accompanied by an increase in reflex tearing. Clinicians often cite this discomfort as a disadvantage of using the Schirmer test in everyday practice. ${ }^{9}$ Several strategies have been employed in an attempt to reduce this patient discomfort, including reducing the test duration from five minutes to one or two minutes. ${ }^{7,9-11}$

Poor reproducibility is another commonly cited weakness when discussing the Schirmer test. ${ }^{10,12,13}$ It is believed that the stimulation of reflex tearing by the filter paper causes a variation in the rate of wetting of the Schirmer strip..$^{9,12,14,15}$ An alternative method of Schirmer testing employs a topical anaesthetic instilled on to the ocular surface prior to application of the filter paper strip. The anaesthetic reduces the initial reflex tearing which is normally produced during the Schirmer test in an attempt to reduce the variability of the test, as well as decreasing the level of discomfort for the patient. However, reflex tearing is not completely suppressed by the use of the anaesthetic, and as such results from this method can still be variable. ${ }^{12}$

The Schirmer test has been employed by a number of researchers to investigate the effects of humidity upon the tear film, ${ }^{16-18}$ and although there have been anecdotal observations that 
environmental humidity may be directly affecting the wetting length of Schirmer strips, ${ }^{4,19-21}$ this effect has never been fully investigated or quantified. Interestingly, a 1967 publication ${ }^{19}$ noted that Schirmer values were consistently lower in patients tested in a lower humidity rheumatic hospital than patients tested in a higher humidity eye hospital. In $2007,{ }^{4}$ it was also suggested that poor reproducibility in the Schirmer test could be due to extrinsic factors such as "temperature, evaporation and humidity". A 2012 paper by Abusharha \& Pearce ${ }^{18}$ found that Schirmer wetting length decreased following a 60 minute exposure to an extremely dry environment within a controlled environment chamber, despite the authors' expectations that tear production would "increase to compensate for increased evaporation" in such an environment.

The purpose of this investigation is to determine if the Schirmer test is affected by environmental humidity, to quantify these effects, if any, and consider the ways in which this may affect the diagnosis of dry eye disease.

\section{$\underline{\text { In Vitro Experiments }}$}

All experiments took place within a controlled environment chamber (CEC) (Weiss-Gallenkamp Ltd, Loughborough, United Kingdom) at a constant temperature of $21^{\circ} \mathrm{C}$ with relative humidity (RH) ranging from $5 \%$ to $95 \%$. The $\mathrm{CEC}$ is able to produce temperatures between $5^{\circ} \mathrm{C}$ and $35^{\circ} \mathrm{C}$ and relative humidity of $5 \%$ to $95 \% \pm 3 \%$.

An in vitro study was conducted to observe the effects of relative humidity on Schirmer wetting, as this allowed the removal of reflex tearing and normal biological variation. In vitro testing employed a mechanical suspension unit to immerse Schirmer strips (Sno Strips, Clement Clarke International Ltd, Harlow, Essex, United Kingdom) at a $5 \mathrm{~mm}$ depth in an unlimited supply of water. The wetting length of the Schirmer strips was marked with a fine-tipped felt pen after each minute of the five minute test period. Six Schirmer strips were recorded at each relative humidity tested.

All data were analysed using SPSS software version 21 (IBM). A test of normality was carried out (Kolmogorov-Smirnov), and all data were found to not follow a normal distribution. Therefore non- 
parametric testing was used to analyse the data. A $P$ value of less than 0.05 was considered a statistically significant difference.

The results of the in vitro study showed a clear decrease in Schirmer wetting length as relative humidity was reduced, a change which was of statistical significance (Mann-Whitney test) with the exception of the change from 50\%RH to 35\%RH (Figure $1(a)$ ). Median wetting length ranged from $27 \mathrm{~mm}$ at $5 \% \mathrm{RH}$ to $39 \mathrm{~mm}$ at $95 \% \mathrm{RH}$.

The rate of wetting of in vitro Schirmer strips was initially very similar, however as the test duration progressed the wetting rate of the Schirmer strips at low humidity decreased by a much greater factor than the decrease in wetting rate seen in the strips at high humidity (Figure $1(b)$ ).

These results indicated that environmental humidity was affecting Schirmer wetting length and wetting rate, and so a modified Schirmer test was then developed in an attempt to find a solution to this problem. An in vitro study was conducted using Schirmer strips sheathed within a plastic film, in order to reduce the effects of evaporation. The plastic sheath began at the $10 \mathrm{~mm}$ notch on the Schirmer strip to ensure the sterility of the strip was maintained. 


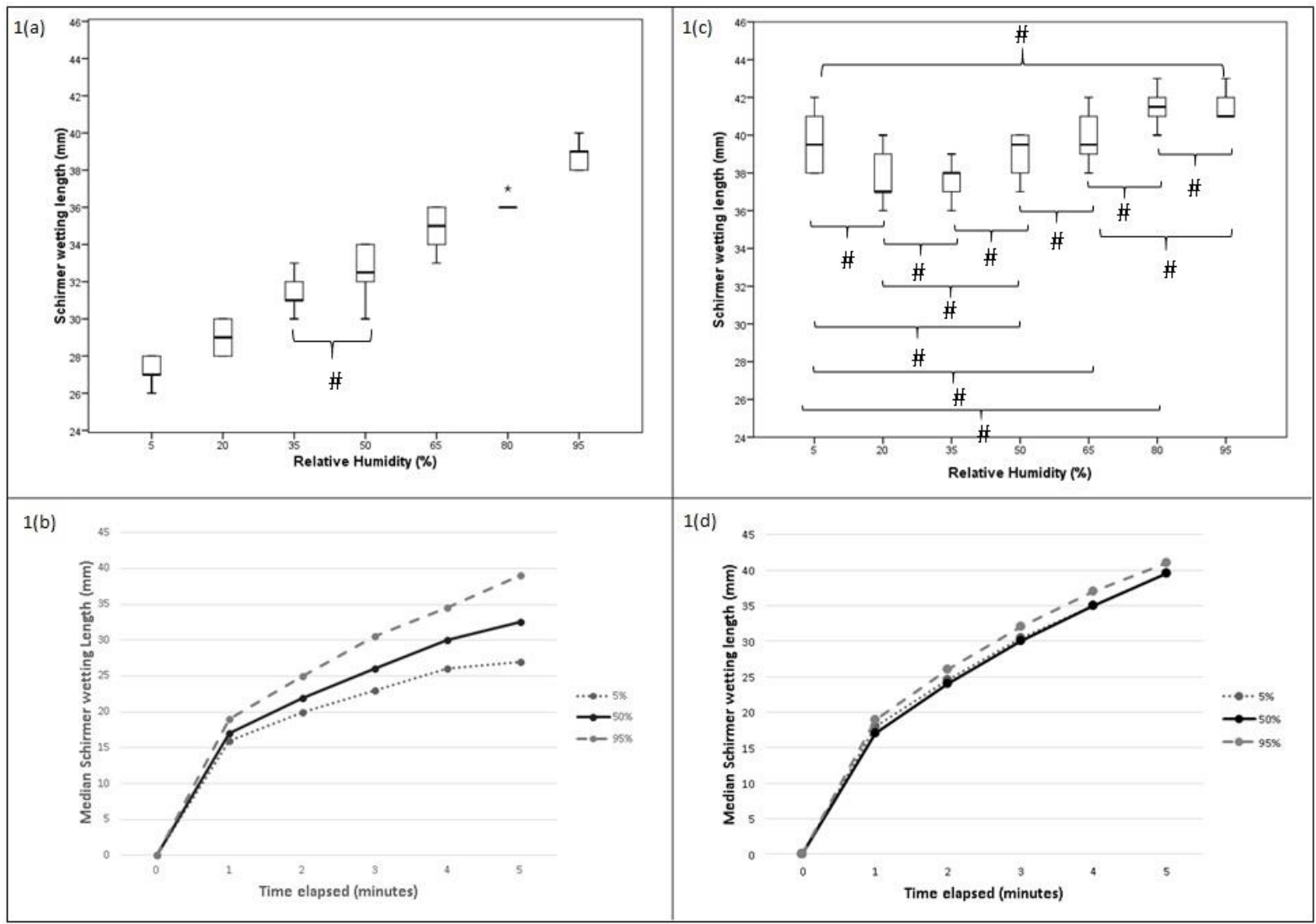

A box plot was employed to show the distribution of in vitro data. The top of the upper whisker of the plot represents the maximum value; the bottom of the lower whisker of the plot represents the minimum value. The median value is represented by the thick middle line in the plot. Figure 1(a): In vitro 5-minute wetting length of standard Schirmer strips decreased as relative humidity is reduced. All were statistically different with the exception of $35 \%$ RH to $50 \%$ RH. Figure 1(b): The line graph shows the rate of wetting of in vitro standard Schirmer strips at 5\%RH, 50\%RH and 95\%RH. The rate of wetting was initially similar at all levels of relative humidity. As the test duration progressed the wetting rate of Schirmer strips at low humidity decreased more than the wetting rate of Schirmer strips at high humidity. Figure 1(c): In vitro Schirmer strips encased within a plastic sheath displayed less variation in 5-minute wetting length than the standard Schirmer strips. Fewer statistical differences were found when the data were analysed using SPSS software. Figure 1(d): The wetting rate of in vitro Schirmer strips encased within a plastic sheath were similar at all levels of relative humidity throughout the entire test duration.

Key: \# = no statistical difference

The results of the study using sheathed Schirmer strips showed a reduction in the change in wetting lengths compared to the previous study using standard Schirmer strips (Figure 1(c)). Statistical 
analysis showed that the number of statistical differences in the data had reduced from 20 out of 21 comparisons to 9 out of 21 comparisons.

The rate of wetting of in vitro sheathed Schirmer strips was shown to be unchanged at all levels of relative humidity throughout the test duration (Figure $1(d)$ ).

\section{$\underline{\text { In Vivo Experiments }}$}

In vivo experimentation was undertaken to investigate the effects of humidity upon the Schirmer test when performed on the human eye. Participants were recruited regardless of dry eye status. Participants were excluded if they displayed signs of active ocular infection or had history of recent ocular surgery. These experiments were approved by the human ethics committee of the School of Health and Life Sciences, Glasgow Caledonian University. Participants attended three sessions on separate days. Each session was conducted at a different relative humidity. Experiments were conducted at $20 \% \mathrm{RH}, 50 \% \mathrm{RH}$ and $80 \% \mathrm{RH}$. These levels of relative humidity were selected as they were unlikely to cause discomfort to the participant during the test period. The number of relative humidities tested was reduced during in vivo testing for practical reasons. The order of RH testing was randomised for each participant. The Schirmer test was performed immediately upon entering the CEC, to ensure the participant's tear film had not yet adapted to the environmental conditions. ${ }^{18}$ Ten participants completed three sessions, 6 male and 4 female. All participants had previously experienced the Schirmer test before beginning the study, in order to negate any "test anxiety" $\mathrm{effect}^{20}$ by which reflex tearing reduces after the first test experience due to a familiarity with the procedure. The Schirmer test was performed using the standardised clinical procedure, the folded end of the filter paper strip was placed over the inferior lid margin $2 \mathrm{~mm}$ from the temporal canthus for a test time of 5 minutes. The participants' eyes were closed for the duration of the test period and no anaesthetic was used. 
The in vivo experiments were conducted using both standardised Schirmer strips and Schirmer strips sheathed within a plastic film. Paired statistical analysis was completed on each individual participant's results.

The in vivo results for standard Schirmer strips showed a decrease of wetting length as relative humidity was reduced (Figure 2(a)). A statistical difference was found between Schirmer wetting at $20 \% \mathrm{RH}$ and $80 \% \mathrm{RH}$ when paired statistical analysis was undertaken. Participants with very low Schirmer wetting lengths displayed very little change in Schirmer test results, whereas participants with moderate to high Schirmer wetting lengths showed much greater change in test results (Figure 2(b)).

In vivo testing of sheathed Schirmer strips displayed much less variation in wetting length than that observed with the standard Schirmer strips (Figure 2(c)). Paired statistical analysis showed no statistical difference in sheathed Schirmer strip wetting length for any of the relative humidities tested.

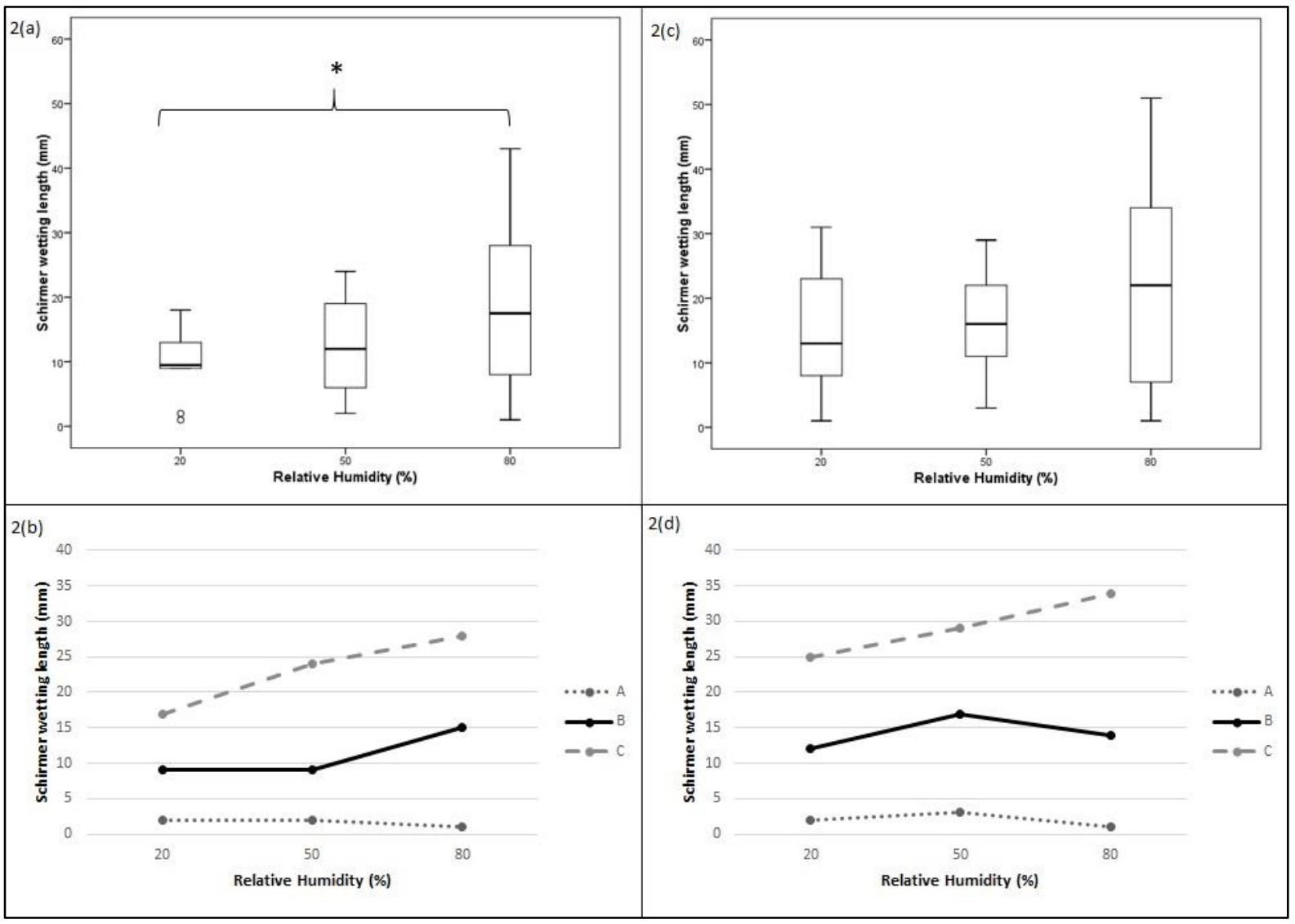


Figure 2(a): In vivo standard Schirmer tests showed a decrease in wetting length as relative humidity is reduced. A statistical difference was found between the wetting length observed at $20 \%$ RH and $80 \%$ RH. Figure 2(b): Participants with very low Schirmer wetting lengths are much less affected by environmental humidity than participants with moderate to high Schirmer wetting lengths. Figure 2(c): In vivo sheathed Schirmer tests showed no statistically significant change in wetting length. Figure 2(d): Participants with moderate to high Schirmer wetting lengths have a general increase in Schirmer test results when tested with sheathed Schirmer strips when compared to standard Schirmer strips.

$$
\text { Key: * statistically different }
$$

The participants in Figure 2(b) and Figure 2(d) were chosen as they show how Schirmer results are affected in individuals with dry eye disease (Participant A, 2mm wetting length at 50\%RH), with results borderline in the diagnostic criteria (Participant $\mathrm{B}, 9 \mathrm{~mm}$ wetting at $50 \% \mathrm{RH}$ ), and with normal tear production (Participant C, 24mm wetting at 50\% RH).

\section{$\underline{\text { Discussion }}$}

The results of this study show a clear decrease in wetting length as relative humidity was reduced in standard Schirmer strips. This variation may be a product of the evaporation of tears from the surface of the Schirmer strip during the test period. Lower relative humidity levels could cause an increase in surface evaporation from the strip, as the difference in water concentration between the strip surface and the surrounding air was much greater than at high levels of relative humidity. To test this hypothesis an infrared thermal imaging camera was employed. It was observed that the surface of the strip does indeed becomes colder through the process of evaporative cooling (Figure 3(a)).

It was observed that participants with low Schirmer results were less affected by the environmental conditions than those participants with normal to high Schirmer wetting lengths (Figure 2(b)). Therefore Schirmer values for patients with dry eye will be unaffected by this phenomenon and so they will be correctly diagnosed. However, patients whose Schirmer wetting length is borderline $(\sim 10 \mathrm{~mm})^{2}$ have the potential to be falsely diagnosed as having dry eye disease if their test is 
undertaken in a low humidity environment. This is shown in Participant B in Figure 2(b), whose Schirmer wetting length is $15 \mathrm{~mm}$ at $80 \% \mathrm{RH}$, however at $20 \% \mathrm{RH}$ their wetting length reduced to 9mm (a "positive" test result for dry eye disease). It should however be noted that there is no gold standard test for dry eye disease, and it is generally accepted that a "battery"22,23 of tests is best practice for diagnosis. Interestingly, Participant B did not test "positive" for dry eye disease at any level of relative humidity when sheathed Schirmer strips were used, showing the utility of the modification (Figure 2(d)).

While this phenomenon may be overcome in clinical practice with the use of a battery of tests for diagnosis, this issue has not been addressed in previous research when investigating the effects of humidity upon the tear film itself. ${ }^{16-18}$ It could therefore be speculated that the results of these studies may have been affected by the effect we have observed and quantified in this study.

Previous literature has shown that the wetting rate of a Schirmer strip is initially rapid, then decreases significantly after 2 minutes of the 5 minute test time has elapsed. ${ }^{9,14}$ This has been attributed to the initial reflex tear secretion which is stimulated by the application of the filter paper strip, which decreases as sensory adaptation occurs, i.e. the subject becomes accustomed to the presence of the Schirmer strip. The in vitro data indicates that there is a reduction in rate of wetting over time even in the absence of reflex tearing (Figure $1(a)$ ). This reduction in wetting rate appeared to be greater at lower levels of relative humidity. We have shown in these studies that the plastic sheathing reduced the reduction in wetting rate seen at lower levels of relative humidity (Figure $1(c)$ ). It could therefore be argued that although there is certainly a sensory adaptation effect in place, surface evaporation of tears occurring from the Schirmer strip also plays a part in the reduction of the wetting rate.

Environmental humidity varies diurnally, annually and from location to location. ${ }^{24}$ It is therefore impossible to ensure that relative humidity is constant every time the Schirmer test is performed anywhere in the world. It may be possible to develop a correction factor to account for variation in test conditions, however this study focused on modifying the Schirmer strip itself to create a new method which is less affected by environmental humidity. It is hoped that manufacturers will take an interest in developing this product. The use of a plastic sheath encasing the Schirmer strip reduces the 
amount of surface evaporation from the strip (Figure $3(b)$ ). This therefore reduces the amount of variation caused by environmental conditions, indicating that it may be possible to modify the Schirmer strip in order to overcome the effect of relative humidity. The authors hope that these findings may revitalise the Schirmer test, perhaps helping to ensure it remains a staple of dry eye diagnosis for another 100 years.

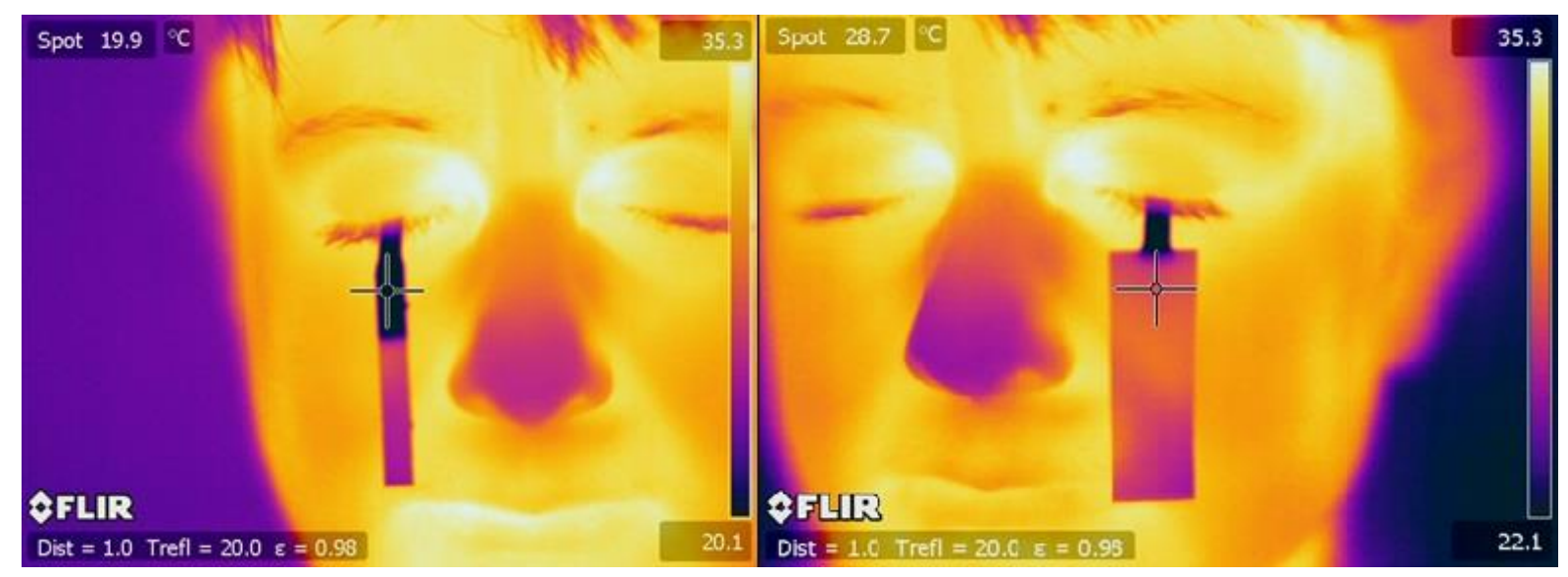

Figure 3(a): Infrared thermal imaging shows the wet portion of the Schirmer strip is colder than the dry portion of the strip at $5 \%$ relative humidity (temperature of spot $=19.9{ }^{\circ} \mathrm{C}$ ), an environmental condition that was selected to best display this phenomenon. This change in temperature is due to evaporative cooling which occurs when water evaporates from the surface of the Schirmer strip during the test. Figure 3(b): Infrared thermal imaging shows that the sheathed portion of the Schirmer strip does not decrease in temperature due to evaporative cooling at 5\%RH, as there is no evaporation occurring behind the plastic sheath (temperature of

$$
\text { spot } \left.=28.7^{\circ} \mathrm{C}\right) \text {. }
$$

\section{$\underline{\text { Acknowledgements }}$}

This study was funded by a summer research scholarship to Fiona Buckmaster (FB) from CooperVision UK. The results of this study were presented in part at CooperVision's National Student Summit in Hampshire, UK in September 2014, where FB was awarded UK Student of the Year 2014. The results of this study were subsequently presented in part at CooperVision's European Future of Ocular Research Creativity Event (FORCE) in Budapest, Hungary, in April 2015, where FB was awarded European FORCE Student of the Year 2015. The author would like to thank Karl Aberdeen and CooperVision UK for their support. 


\section{$\underline{\text { References }}$}

1. The definition and classification of dry eye disease: report of the Definition and Classification Subcommittee of the International Dry Eye WorkShop (2007). Ocul. Surf. 2007;5(2):75-92.

2. Schirmer O. Studien zur Phisiology und Pathologie der Tranenabsonderung und Tranenabfuhr. Graefes Arch Clin Exp Ophthalmol 1903;56:197-291.

3. Cho P, Yap M. Schirmer test. I. A review. Optom. Vis. Sci. 1993;70(2):152-6.

4. Serin D, Karsloğlu S, Kyan A, Alagöz G. A simple approach to the repeatability of the Schirmer test without anesthesia: eyes open or closed? Cornea 2007;26(8):903-6.

5. Masmali A, Alqahtani TA, Alharbi A, El-Hiti GA. Comparative study of repeatability of phenol red thread test versus Schirmer test in normal adults in Saudi Arabia. Eye Contact Lens 2014;40(3):127-31.

6. Methodologies to diagnose and monitor dry eye disease: report of the Diagnostic Methodology Subcommittee of the International Dry Eye WorkShop (2007). Ocul. Surf. 2007;5(2):108-52.

7. Bawazeer AM, Hodge WG. One-minute schirmer test with anesthesia. Cornea 2003;22(4):285-287.

8. Jones L. The lacrimal secretory system and its treatment. Am. J. Ophthalmol. 1966;62(1):4760.

9. Karampatakis V, Karamitsos A, Skriapa A, Pastiadis G. Comparison between normal values of 2- and 5-minute Schirmer test without anesthesia. Cornea 2010;29(5):497-501.

10. Jones L, Marquis M, Vincent N. Lacrimal function. Am. J. Ophthalmol. 1972;73(5):658-659.

11. Kashkouli MB, Pakdel F, Amani A, Asefi M. C LINICAL S CIENCE A Modified Schirmer Test in Dry Eye and Normal Subjects : Open Versus Closed Eye and 1-Minute Versus. 2010:384-387.

12. Clinch TE, Benedetto DA, Felberg NT, Laibson PR. Schirmer's test. A closer look. Arch. Ophthalmol. 1983;101(9):1383-6. 
13. Feldman F, Wood MM. Evaluation of the Schirmer tear test. Can. J. Ophthalmol. 1979;14(4):257-259.

14. Williams DL. Analysis of tear uptake by the Schirmer tear test strip in the canine eye. Vet. Ophthalmol. 2005;8(5):325-330.

15. Holly FK, LauKaitis SJ, Esquivel ED. Kinetics of lacrimal secretions in normal human subject. Curr. Eye Res. 1984;3(7):897-910.

16. Tesón M, González-García MJ, López-Miguel A, et al. Influence of a controlled environment simulating an in-flight airplane cabin on dry eye disease. Invest. Ophthalmol. Vis. Sci. 2013;54(3):2093-9.

17. López-Miguel A, Tesón M, Martín-Montañez V, et al. Dry eye exacerbation in patients exposed to desiccating stress under controlled environmental conditions. Am. J. Ophthalmol. 2014;157(4):788-798.e2.

18. Abusharha A a, Pearce EI. The effect of low humidity on the human tear film. Cornea 2013;32(4):429-34.

19. Williamson J, Allison M. Effect of temperature and humidity in the Schirmer tear test. Br. J. Ophthalmol. 1967;51(9):596-8.

20. Nichols KK, Mitchell GL, Zadnik K. The repeatability of clinical measurements of dry eye. Cornea 2004;23(3):272-85.

21. Hypher TJ. Fluid uptake in Schirmer papers and its relevance to their employment in tear collection for lysozyme tests. Br. J. Ophthalmol. 1980;64(9):696-99.

22. Alves M, Reinach PS, Paula JS, et al. Comparison of diagnostic tests in distinct well-defined conditions related to dry eye disease. PLoS One 2014;9(5):e97921.

23. Pflugfelder SC, Solomon A, Stern ME. The diagnosis and management of dry eye: a twentyfive-year review. Cornea 2000;19(5):644-9.

24. Brimblecombe P. Temporal humidity variations in the heritage climate of South East England. 
Herit. Sci. 2013;1(1):3. 


\section{Figure Legends}

A box plot was employed to show the distribution of in vitro data. The top of the upper whisker of the plot represents the maximum value; the bottom of the lower whisker of the plot represents the minimum value. The median value is represented by the thick middle line in the plot. Figure 1(a): In vitro 5-minute wetting length of standard Schirmer strips decreased as relative humidity is reduced. All were statistically different with the exception of 35\%RH to 50\%RH. Figure 1(b): The line graph shows the rate of wetting of in vitro standard Schirmer strips at 5\%RH, 50\%RH and 95\%RH. The rate of wetting was initially similar at all levels of relative humidity. As the test duration progressed the wetting rate of Schirmer strips at low humidity decreased more than the wetting rate of Schirmer strips at high humidity. Figure 1(c): In vitro Schirmer strips encased within a plastic sheath displayed less variation in 5-minute wetting length than the standard Schirmer strips. Fewer statistical differences were found when the data were analysed using SPSS software. Figure 1(d): The wetting rate of in vitro Schirmer strips encased within a plastic sheath were similar at all levels of relative humidity throughout the entire test duration. Key: \# = no statistical difference

Figure 2(a): In vivo standard Schirmer tests showed a decrease in wetting length as relative humidity is reduced. A statistical difference was found between the wetting length observed at 20\%RH and 80\%RH. Figure 2(b): Participants with very low Schirmer wetting lengths are much less affected by environmental humidity than participants with moderate to high Schirmer wetting lengths. Figure 2(c): In vivo sheathed Schirmer tests showed no statistically significant change in wetting length. Figure 2(d): Participants with moderate to high Schirmer wetting lengths have a general increase in Schirmer test results when tested with sheathed Schirmer strips when compared to standard Schirmer strips. Key: $*$ statistically different

Figure 3(a): Infrared thermal imaging shows the wet portion of the Schirmer strip is colder than the dry portion of the strip at 5\% relative humidity (temperature of spot $=19.9{ }^{\circ} \mathrm{C}$ ), an environmental condition that was selected to best display this phenomenon. This change in temperature is due to evaporative cooling which occurs when water evaporates from the surface of the Schirmer strip during the test. Figure 3(b): Infrared thermal imaging shows that the sheathed portion of the 
Schirmer strip does not decrease in temperature due to evaporative cooling at 5\%RH, as there is no evaporation occurring behind the plastic sheath (temperature of spot $=28.7^{\circ} \mathrm{C}$ ). 